\title{
ArtigoOrigne
}

\section{DESENVOLVIMENTO PRÉEMBRIONÁRIO EM RATAS TRATADAS COM OXCARBATEPINA NOS QUATRO PRIMEIROS DIAS APÓS A INSEMINAÇÃO}

*M. de O. Gugrpa, Le. G. de Ouvara,V. M. Petras

Centro de Biologia da Reprodução-UniversidadeFederaldeJuiz deFora-M G

RESUMO - A oxcarbazepina é uma droga antiepiléptica de alta eficácia e poucos efeitos colaterais, mas pouco estudada quanto a seus efeitos durante a gestação humana e animal.

OBjetivo. Verificar se a administração de oxcarbazepine em ratas, nos quatro primeiros dias após a inseminação, altera a viabilidade ou o desenvolvimento do pré-embrião.

Métodos, Ratas Wistar foram tratadas com 20 ou $200 \mathrm{mg}$ de oxcarbazepina/ Kg de peso corporal, via gástrica, nosdias 1, 2,3, ou 4 a partir da inseminação ou, consecutivamente, do 10 ao 40. 0 spréembriōes foram coletados no quinto dia, visando verificar a quantidadee odesenvolvimento atéafase deblastocisto expandido. 0 peso corporal materno e sinais como pelos eriçados e alteração de atividade locomotora foram anotados para verificar indícios de toxicidade materna. Número de corpos lúteos e peso de ovários foram anotados com vistas à capacidade reprodutiva do animal.

RESULTADOS. Não ocorreram perdas de pesos corporais maternos e nenhuma alteração física indicativa de desconforto para as ratas. Peso de ovários e número de corpos lúteos não diferiram entre tratadose controles. 0 número médio de pré-embriões por mães, o índice de perdas embrionárias, a proporção de blastocistos expandidos com relação ao total de pré-embriõese a média de blastocistos expandidos/mãe, não diferiram entre tratados e controles.

Conclusäo. A oxcarbazepina administrada em ratas, seguindo o esquema terapêutico mencionado, não apresentou efeito tóxico sobre a mãe e não alterou o desenvolvimento do pré-embrião.

UnITERMOs: Oxcarbazepine. Pré-embrião. Rata.

\section{INTRODUÇão}

Cercade $0,5 \%$ de mulheresgestantes são epilépticas e precisam usar anticonvulsivantes continuamente já que com a interrupção do tratamento podem surgir crises convulsivas e conseqüente risco fetal por hipóxia intra-uterina ${ }^{1,2}$. Entretanto, drogas antiepilépticas eficientescomo o ácido valpróico ea carbamazepinatêm apresentado efeito teratogênico em humanos $5^{3,4}$. Embora 0 efeito teratogênico também possa ser atribuído afatores genéticos, associados com a própria enfermidade ${ }^{5}$, 0 fato é que fetos de mães epilépticas estão sujeitos aum risco duplo - a

*Correspondênda

R. São M atheus, 711 -apte103-C -Cep: 36026-001 Juiz deFora/ M G -Tel.: (32)229-3253 E-mail:moguerra@cbr.ufif.br epilepsiae as drogas anticonvulsivantes ${ }^{6}$.

A oxcarbazepina (OXC) é uma nova droga anticonvulsivante, estruturalmente relacionada à carbamazepina, que exibe espectro farmacológico e potênciasemeInantes à da carbamazepina, porém com menor freqüência de efeitos colaterais ${ }^{7-10}$.

Há relato de um caso de tratamento monoterápico com OXC $(300 \mathrm{mg} / 3$ vezes ao dia), efetuado inadvertidamentedesdeo terceiro mês de gestação, que resultouem um recém-nascido saudável ${ }^{11}$. Além disso, um estudo retrospectivo de 947 pacientes tratadas com OXC mostrou que em 12 gestações, nove recém-nascidoseram saudáveis ${ }^{12}$, não havendo informações sobre ostrêscasos restantes.

São escassos os estudos em animais de laboratório, visando a avaliação do potencial teratogênico da 0 XC. Háum relato de que seria desprovida de efeitos sobre a fertilidade de ratose de camundongos; de teratogenicidadee, quenenhum efeito cognitivo indesejável seria evidenciável, quando aadministração ocorreu no estágio final dagestação ouno perío do de lactaçãa ${ }^{13}$. A referênciatratade trabalhos do laboratório produtor do medicamento, apresentados em relatóriosinternose sobre os quaisnão foram encontradas publicaçõesnaliteratura. 0 utra publicação menciona que não ocorreudiferençasignificativano índicede malformações, quando foram comparadas ratas controles etratadas com 1.100mgde $0 \times C / K g / d i a^{14}$.

$N$ ão foram encontradosestudos visando afase inicial do desenvolvimento embrionário, quando a morte do pré-embrião, pode não ser detectadae, assim, confundidacom infertilidade. 
Dada a necessidade de informações sobre as conseqüências do uso da $\mathrm{OXC}$ durante todo o período de gestação, nesse trabalho pretende-se verificar se aadministração do medicamento em ratas interfere com o desenvolvimento do pré-embrião durante o seu trânsito pelo oviduto.

\section{Material e Métodos}

\section{Animaisdeexperimentação}

Foram usadas ratas, originalmenteW istar, com trêsmeses de idade, dacolôniado Biotério do Centro de BiologiadaReprodução - U niversidade Federal de Juiz deFora, pesando em média 180 a $200 \mathrm{~g}$.

\section{ProcedimentoExperimental}

O sanimais foram acasalados com machosdefertilidade previamente comprovada e a presença de espermatozóide no esfregaço vaginal foi considerada indicativa de inseminação, sendo este dia designado 0 primeiro pós-fertilização ${ }^{15,16}$.

Asratasinseminadasforam distribuídas aleatoriamente em três grupos: controle, tratado-20 (T-20) e tratado-200 (T-200). 0 grupo controle recebeu $0,5 \mathrm{ml}$ de água destilada, 0 grupo T-20, 20mg de oxcarbazepina diluídaem 0,5 ml deáguadestilada /Kg de peso corporal e o grupo T-200, $200 \mathrm{mgde}$ oxcarbazepina/Kgde peso corporal. Águae oxcarbazepinaforam administradas por sonda gástrica às 9 he às $12 \mathrm{~h}$.

As doses escolhidasforam baseadasna dose terapêutica preconizada para o ser humano (1200 mg/dia), e nas dosesusadas para o estudo do efeito anticonvulsivante em ratos: $5,10,30,60 \mathrm{mg}^{17}$ e 40 ou $80 \mathrm{mg}$ $0 \times \mathrm{C} / \mathrm{Kg}$ de peso corporal de rato ${ }^{18}$.

\section{Aveliaçãododesenvolvimentopréembrionário}

Paraaavaliação do pré-embrião, durante o seu trajeto pelo oviduto até a chegada ao útero, foram realizados os seguintes experimentos (cada experimento compreendeu um lote de 15 animais):
Tabela 1- Peso corporal de ratas Wistar tratadas com $20 \mathrm{mg}$ ou $200 \mathrm{mg}$ de oxcarbazepina / Kg de peso corporal, via gástrica, nos dias 1, 2, 3 ou 4 pós- inseminação, e de controles que receberam $0,5 \mathrm{ml}$ de água destilada pela mesma via e nos mesmos diasdetratamento.

\begin{tabular}{|c|c|c|c|c|c|}
\hline \multirow[t]{2}{*}{ Experimentos } & \multirow[t]{2}{*}{ Grupos } & \multicolumn{4}{|c|}{ Peso Corporal (g) } \\
\hline & & \multicolumn{2}{|c|}{ Início do tratamento } & \multicolumn{2}{|c|}{ Sacrifício } \\
\hline \multirow[t]{3}{*}{ I } & Controle & $173,4 \pm 10,2$ & (15) & $180,3 \pm 12,2$ & (15) \\
\hline & Tratado - 20 & $177,3 \pm 15,1$ & (15) & $185,9 \pm 15,7$ & (15) \\
\hline & Tratado - 200 & $175,9 \pm 13,8$ & (16) & $181,1 \pm 15,6$ & (16) \\
\hline \multirow[t]{3}{*}{$\|$} & Controle & $171,6 \pm 14,5$ & (15) & $175,7 \pm 14,9$ & (15) \\
\hline & Tratado - 20 & $181,7 \pm 15,7$ & (15) & $186,9 \pm 16,5$ & (15) \\
\hline & Tratado - 200 & $178,7 \pm 11,3$ & (17) & $183,3 \pm 11,3$ & (17) \\
\hline \multirow[t]{3}{*}{ III } & Controle & $172,7 \pm 14,3$ & (15) & $176,9 \pm 13,7$ & (15) \\
\hline & Tratado - 20 & $180,1 \pm 15,9$ & (15) & $181,9 \pm 16,7$ & (15) \\
\hline & Tratado - 200 & $184,5 \pm 13,6$ & (15) & $186,3 \pm 13,2$ & (15) \\
\hline \multirow[t]{3}{*}{ IV } & Controle & $168,4 \pm 15,8$ & (17) & $166,9 \pm 15,7$ & (17) \\
\hline & Tratado - 20 & $180,5 \pm 14,9$ & (15) & $180,2 \pm 12,8$ & (15) \\
\hline & Tratado - 200 & $182,7 \pm 13,8$ & (15) & $181,5 \pm 13,3$ & (15) \\
\hline
\end{tabular}

Resultados expressos em média \pm desvio padrão, ( ) n.0 de casos estudados.

Tabela 2 - Peso corporal de ratas Wistar tratadas com $20 \mathrm{mg}$ ou $200 \mathrm{mg}$ de oxcarbazepina / Kg de peso corporal, via gástrica, do 10 ao 40 dia pós- inseminação, e de controles que receberam $0,5 \mathrm{ml}$ de água destilada pela mesma via e mesmosdias detratamento.

\begin{tabular}{lllllll}
\hline Grupos & \multicolumn{5}{c}{ Peso Corporal (g) } \\
\cline { 2 - 7 } & $\begin{array}{c}\text { Início do } \\
\text { tratamento }\end{array}$ & \multicolumn{4}{c}{$\begin{array}{c}\text { Fim do } \\
\text { Tratamento }\end{array}$} & Sacrifício \\
Controle & $165,4 \pm 10,4$ & $(15)$ & $169,1 \pm 12,4$ & $(15)$ & $171,6 \pm 12,4$ & $(15)$ \\
Tratado - 20 & $172,1 \pm 10,9$ & $(15)$ & $176,9 \pm 12,2$ & $(15)$ & $179,6 \pm 12,7$ & $(15)$ \\
Tratado -200 & $176,6 \pm 6,4$ & $(14)$ & $176,5 \pm 5,8$ & (14) & $178,4 \pm 6,8$ & (14) \\
\hline
\end{tabular}

Resultados expressos em média \pm desvio padrão, ( ? ) n.․ de casos estudados. 
Experimento |:Tratamentodasratasno1-dia pós-inseminação.

Experimentoll:Tratamentodasratasno 20 diapós-inseminação

Experimento $|l|$ :Tratamentodasratasno3diapós-inseminação

Experimento IV:Tratamentodasratasno $4^{\circ}$ diapós-inseminação.

ExperimentoV:Tratamentodasratasnosdias

\section{1,2,3e4 pós-inseminação.}

As ratas foram pesadas no dia do tratamento e no dia do sacríício (50 dia de gestação) quefoifeito por excesso de inalação de éter. 0 grupo tratado desde o primeiro atéo quarto diafoi pesado no início do tratamento, no término e no dia do sacrifício.

Durantetodo o experimento os animais foram examinadosparaavaliar sinaisclínicos de toxicidadematerna(mortes, piloereção e alteração nalo comoção $)^{19}$.

Paraacoletade pré-embriões, foram usadas as técnicas de coleta e exame de estruturas embrionárias conforme descrito por Forcelledo, Vera, Croxatto ${ }^{20} \mathrm{e}$ 0 rtiz, Llados, Croxato ${ }^{21}$. Através dessa técnica os ovidutos e cornos uterinos, expostos por laparotomia, são removidos para uma placa de Petri, contendo soro fisiológico. 0 sovidutos são separados da extremidade tubária do corno uterino e ambos são canulados com sonda apropriada por onde se perfunde solução salina. O slavadostubáriose uterinossão recolhidosem cápsulas embrionárias, para posterior exame dos pré-embriões.

Cadacápsulaembrionáriafoi examinada para contagem do número de pré-embriõese para avaliação do seu desenvolvimento até afase de blastocisto expandido.

O s ovários são examinados sob lupa para contagem dos corpos lúteos, estabelecendo-se a relação entre corpos lúteose pré-embriões para adeterminação do índice de perdas embrionárias (IPE = 1-pré-embriōes/corposlúteosX 100).

Tabela 3 - Número de corpos lúteos nos ovários de ratas Wistar tratadas com 20 mg ou $200 \mathrm{mg}$ de oxcarbazepina / Kg de peso corporal, via gástrica, nos dias 1,2,3 ou 4 pósinseminação, e do 10 ao $4^{\circ}$ dia pós-inseminação, e de controles tratadas com $0,5 \mathrm{ml}$ de água destilada pela mesma via e mesmo dias de tratamento.

\begin{tabular}{|c|c|c|c|c|c|c|c|}
\hline \multirow{5}{*}{$\begin{array}{c}\text { Experimentos } \\
1\end{array}$} & \multirow{3}{*}{$\begin{array}{l}\text { Grupos } \\
\text { Controle }\end{array}$} & \multicolumn{6}{|c|}{ Números de Corpos Lúteos no O vário } \\
\hline & & \multicolumn{2}{|l|}{ Direito } & \multicolumn{2}{|c|}{ Esquerdo } & \multicolumn{2}{|l|}{ Total } \\
\hline & & $6,3 \pm 1,9$ & (15) & $5,1 \pm 1,4$ & (15) & $11,4 \pm 1,1$ & (15) \\
\hline & Tratado - 20 & $6,9 \pm 1,6$ & (15) & $5,3 \pm 1,8$ & (15) & $12,2 \pm 1,8$ & (15) \\
\hline & Tratado - 200 & $7,1 \pm 1,7$ & (16) & $4,9 \pm 1,7$ & (16) & $12,1 \pm 1,9$ & (16) \\
\hline \multirow[t]{3}{*}{$\|$} & Controle & $5,9 \pm 2,0$ & (15) & $5,8 \pm 1,8$ & $(15)$ & $11,7 \pm 1,4$ & (15) \\
\hline & Tratado - 20 & $6,5 \pm 1,4$ & (15) & $5,8 \pm 1,8$ & (15) & $12,3 \pm 1,7$ & (15) \\
\hline & Tratado - 200 & $5,9 \pm 2,1$ & (17) & $5,2 \pm 1,9$ & (17) & $11,2 \pm 1,3$ & (17) \\
\hline \multirow[t]{3}{*}{ III } & Controle & $7,0 \pm 1,9$ & (15) & $5,1 \pm 1,3$ & $(15)$ & $12,2 \pm 1,8$ & (15) \\
\hline & Tratado - 20 & $6,1 \pm 1,3$ & (15) & $6,3 \pm 1,9$ & (15) & $12,4 \pm 1,4$ & (15) \\
\hline & Tratado - 200 & $7,7 \pm 1,8$ & (15) & $5,2 \pm 1,9$ & (15) & $13,5 \pm 2,0$ & (15) \\
\hline \multirow[t]{3}{*}{ IV } & Controle & $6,1 \pm 1,6$ & (17) & $4,9 \pm 2,0$ & (17) & $11,0 \pm 1,8$ & (17) \\
\hline & Tratado - 20 & $6,5 \pm 1,2$ & (15) & $5,4 \pm 1,3$ & (15) & $11,9 \pm 1,2$ & (15) \\
\hline & Tratado - 200 & $6,6 \pm 2,3$ & (15) & $5,5 \pm 1,5$ & (15) & $12,1 \pm 1,5$ & (15) \\
\hline \multirow[t]{3}{*}{ V } & Controle & $6,2 \pm 1,5$ & (15) & $5,4 \pm 2,2$ & (15) & $11,6 \pm 1,5$ & (15) \\
\hline & Tratado - 20 & $6,5 \pm 1,6$ & (15) & $5,7 \pm 1,7$ & (15) & $12,1 \pm 1,5$ & (15) \\
\hline & Tratado - 200 & $6,4 \pm 1,7$ & (14) & $5,2 \pm 1,5$ & (14) & $11,6 \pm 1,1$ & (14) \\
\hline
\end{tabular}

Resultados expressos em média \pm desvio padrão, ( ) no de casos estudados.

\section{Processamentoestatístico}

Pesosmaternos antes e depois do tratamento são comparados pelo teste " $\mathrm{t}$ "de Student pareado; o número de pré-embriões coletados foi comparado por Anova, seguida de teste de Dunnet (a $=0,05)$. A proporção de blastocistos expandidosem relação ao total de pré-embriões coletados e o índice de perdas de pré-embriões foram comparados pelo teste do $Q$ ui quadrado $(a=0,05)$.

\section{Resultados}

0 tratamento das ratas com oxcarba- zepina não causou mortes maternas nem alteração de atividadelocomotoraou piloereção. 0 peso corporal das mães não se reduziu após aadministração de oxcarbazepinaoude águadestilada, conformepode ser verificado natabela 1 .

$\mathrm{N}$ atabela 2 encontra-se o peso corporal de ratas que foram tratadas em dias consecutivosapós afertilização, iniciando no primeiro e terminando no quarto dia. Nota-se que não houve perda de peso corporal entre o dia do tratamento e o do sacrifício.

A tabela 3 mostra o número médio de corposlúteospor ovário e o número total, 
Tabela 4 - Peso (g) de ovários de ratas Wistar tratadas com 20 mg ou $200 \mathrm{mg}$ de oxcarbazepina / $\mathrm{Kg}$ de peso corporal, via gástrica, nos dias 1, 2, 3 ou 4 pós- inseminação, e do 10 ao 40 dia pós- inseminação, e de controles que receberam $0,5 \mathrm{ml}$ de água destilada pela mesma via e mesmos dias de tratamento.

\begin{tabular}{|c|c|c|c|c|c|}
\hline \multirow{3}{*}{$\begin{array}{l}\text { Experimentos } \\
1\end{array}$} & \multirow[t]{2}{*}{ Grupos } & \multicolumn{4}{|c|}{ Peso de Ovários* } \\
\hline & & \multicolumn{2}{|c|}{ Direito } & \multicolumn{2}{|l|}{ Esquerdo } \\
\hline & Controle & $173,4 \pm 10,2$ & (15) & $180,3 \pm 12,2$ & (15) \\
\hline \multirow[t]{3}{*}{1} & Controle & $0,022 \pm 0,004$ & (15) & $0,019 \pm 0,003$ & (15) \\
\hline & Tratado - 20 & $0,025 \pm 0,003$ & (15) & $0,021 \pm 0,003$ & (15) \\
\hline & Tratado - 200 & $0,027 \pm 0,004$ & $(16)^{* *}$ & $0,022 \pm 0,003$ & (16) \\
\hline \multirow[t]{3}{*}{$\|$} & Controle & $0,023 \pm 0,004$ & (15) & $0,023 \pm 0,003$ & (15) \\
\hline & Tratado - 20 & $0,026 \pm 0,004$ & (15) & $0,025 \pm 0,004$ & (15) \\
\hline & Tratado - 200 & $0,023 \pm 0,005$ & (17) & $0,020 \pm 0,003$ & $(17)^{* *}$ \\
\hline \multirow[t]{3}{*}{ III } & Controle & $0,024 \pm 0,004$ & (15) & $0,020 \pm 0,002$ & (15) \\
\hline & Tratado - 20 & $0,022 \pm 0,003$ & (15) & $0,021 \pm 0,004$ & (15) \\
\hline & Tratado - 200 & $0,028 \pm 0,004$ & $(15)^{* * *}$ & $0,023 \pm 0,005$ & (15) \\
\hline \multirow[t]{3}{*}{ IV } & Controle & $0,025 \pm 0,004$ & (17) & $0,022 \pm 0,006$ & (17) \\
\hline & Tratado - 20 & $0,026 \pm 0,005$ & (15) & $0,023 \pm 0,003$ & (15) \\
\hline & Tratado - 200 & $0,025 \pm 0,005$ & (15) & $0,021 \pm 0,003$ & (15) \\
\hline \multirow[t]{3}{*}{ V } & Controle & $0,022 \pm 0,003$ & (15) & $0,021 \pm 0,004$ & (15) \\
\hline & Tratado - 20 & $0,024 \pm 0,004$ & (15) & $0,021 \pm 0,004$ & (15) \\
\hline & Tratado - 200 & $0,021 \pm 0,003$ & (14) & $0,019 \pm 0,002$ & (14) \\
\hline
\end{tabular}

Resultados expressos em média \pm desvio padrão, ( ) n.o de casos estudados.

** $p<0.05$ em relação ao grupo controle (Teste de Dunnet)

*** $p<0.05$ em relação ao grupo controle (Teste de Dunnet)

nos dois ovários, de ratas submetidas aos diferentesexperimentos. $\mathrm{N}$ ota-se que não ocorreram diferençassignificativas nosnúmeros de corpos lúteos encontrados em cada ovário ou quando se efetuou a soma dos corpos lúteos dos do is ovários.

0 peso médio dos ovários, em cada grupo experimental, estáexpresso natabela 4, onde se observa que os ovários dos animais tratados com 200 mg de oxcarbazepina / Kg de peso corporal, foram mais pesados que os de controle, nos experimentos I e III. 0 ovário esquerdo dos mesmos animais foram menores que os controles no experimento II. N os lavados detubauterinanão foram encontradospréembriões.

A média de pré-embriões por corno uterino e em ambos cornos, encontra-se expressa na tabela 5. Comparativamente aos grupos controles, os animais tratados comoxcarbazepinanão apresentaram dife- rençano número de pré-embriões ou estes foram maisnumerosos(Experimento lell) que noscontroles.

0 índice de perdas pré-embrionárias em cada grupo experimental, encontra-se expresso natabela6. Verifica-se que a perdaembrionáriafoi semelhante nosgrupos controleetratados.

A tabela 7 apresenta o percentual de blastocistos expandidos encontrados nos cornosuterinos direito eesquerdo, apartir daequação (Blastocistosexpandidos/Total de pré-embriões) x 100. N ão há diferença significativa entreosgrupos.

\section{Discussão e Conclusões}

No presente trabalho tratou-se de avaliar se a oxcarbazepina, administrada em ratas durante o período pré-embrionário, causaria sua morte ou alteração do desenvolvimento até a fase de blastocisto.

Emestudosdetal naturezaéimportante dissociar a existência de efeitos tóxicossobre a mãe, já que isto, por si só, poderia causar alterações do desenvolvimento embrionário ${ }^{19}$.

$\mathrm{N}$ ão foram observadas mortes maternas ou alteração de atividade locomotorae presençade pêlos eriçados, indicativos de toxicidade e desconforto físico dos animais $^{19}$. Como pode ser verificado pelas tabelas 1 e 2, o tratamento efetuado coma oxcarbazepina não causou perda de peso nas mães. Em conjunto, tais dados indicam que, sob o ponto de vista de uma abordagem clínica ${ }^{19}$, a oxcarbazepinanão tem efeito tóxico sobre as mães.

O utraanálise importanteé verificar sea capacidade reprodutiva materna está se desenvolvendo de maneirauniformeentre osgruposexperimentais.

O s corpos lúteos são a fonte principal de secreção de progesterona ${ }^{16}$ e já foi demonstrado que o seu crescimento está intimamente correlacionado com o aumen- 
to de secreção de progesterona e 20 hidroxi-progesterona ${ }^{22}$, hormônios que mantém a gestação da rata. Além disso, os pesos de ováriossão muito dependentes do número e do volume dos corpos lúteos, que aumentam ao longo dagestação ${ }^{23}$.

Por fim, Inman\& Markivee ${ }^{24}$ jádemonstraram que o número de corpos lúteos é uma boa evidência do número de ovulações. Como podeser verificado natabela4, o peso dos ovários, na sua maioria, foi semelhante quando comparados nos três gruposexperimentais. A diferençaestatísticaencontradanão tem significado biológico e deve ser atribuída ao fato de haver maior número de corpos lúteos em um dos ovários. Porém, quando se considerao total de corpos lúteos nos do is ovários (tabela 3), nota-se que o seu número médio não variouentre osgrupos experimentais. Consequentemente, osmecanismosneuroendócrinos responsáveis pelaovulação estão funcionando demaneirauniformeem ratas detodosos grupos experimentaise quaisquer alterações observadas após o tratamento podem ser imputadas aalterações provocadas pelo agente examinado.

Dado que existe uma correlação entre o número de corpos lúteos e o número de ovulações, é habitual que o primeiro também sejacorrelacionado com o número de pré-embriões ${ }^{25}$, pois pressupõem-se que cadaovulação liberaum ovócito que pode ser fecundado e viabilizar-se em um préembrião. 0 índice de perdas pré-embrionárias estabelece a relação entre as duas variáveise, como se depreende dos dados exibidos na tabela 5 , a administração de oxcarbazepina não modificou o índice de perdaspré-embrionárias.

As alterações no desenvolvimento do pré-embrião podem ser devidas a lesão direta ou indireta do agente tóxico. No primeiro caso, alesão édiretamente sobre o concepto e nasegunda, podedecorrer de alteraçõoes dasecreção tubárias ou de mo-

Tabela 5 - Número de pré-embriōes nos cornos uterinos de ratas Wistar tratadas com $20 \mathrm{mg}$ ou $200 \mathrm{mg}$ de oxcarbazepina / $\mathrm{Kg}$ de peso corporal, via gástrica, nos dias 1, 2, 3 ou 4 pós- inseminação, e do 10 ao $4^{0}$ dia pós- inseminação, e de controles que receberam $0,5 \mathrm{ml}$ de água destilada pela mesma via e mesmos dias de tratamento.

\begin{tabular}{|c|c|c|c|c|c|c|c|}
\hline \multirow{5}{*}{$\begin{array}{c}\text { Experimentos } \\
1\end{array}$} & \multirow{3}{*}{$\begin{array}{l}\text { Grupos } \\
\text { Controle }\end{array}$} & \multicolumn{6}{|c|}{ Pré-embriões nos cornos uterinos } \\
\hline & & \multicolumn{2}{|c|}{ Direito } & \multicolumn{2}{|c|}{ Esquerdo } & \multicolumn{2}{|l|}{ Total } \\
\hline & & $4,7 \pm 1,9$ & $(15)^{*}$ & $5,1 \pm 1,4$ & (15) & $11,4 \pm 1,1$ & $(15)^{*}$ \\
\hline & Tratado - 20 & $6,1 \pm 1,6$ & (15) & $5,3 \pm 1,8$ & (15) & $12,2 \pm 1,8$ & (15) \\
\hline & Tratado - 200 & $6,2 \pm 1,7$ & (16) & $4,9 \pm 1,7$ & (16) & $12,1 \pm 1,9$ & (16) \\
\hline \multirow[t]{3}{*}{$\|$} & Controle & $4,9 \pm 2,0$ & (15) & $5,8 \pm 1,8$ & (15) & $11,7 \pm 1,4$ & $(15)^{*}$ \\
\hline & Tratado - 20 & $6,0 \pm 1,4$ & (15) & $5,8 \pm 1,8$ & (15) & $12,3 \pm 1,7$ & $(15)$ \\
\hline & Tratado - 200 & $5,2 \pm 2,1$ & (17) & $5,2 \pm 1,9$ & $(17)$ & $11,2 \pm 1,3$ & (17) \\
\hline \multirow[t]{3}{*}{ III } & Controle & $6,1 \pm 1,9$ & (15) & $5,1 \pm 1,3$ & (15) & $12,2 \pm 1,8$ & (15) \\
\hline & Tratado - 20 & $5,3 \pm 1,3$ & (15) & $6,3 \pm 1,9$ & (15) & $12,4 \pm 1,4$ & (15) \\
\hline & Tratado - 200 & $6,5 \pm 1,8$ & (15) & $5,9 \pm 1,9$ & (15) & $13,5 \pm 2,0$ & (15) \\
\hline \multirow[t]{3}{*}{ IV } & Controle & $5,2 \pm 1,6$ & (17) & $4,9 \pm 2,0$ & (17) & $11,0 \pm 1,8$ & (17) \\
\hline & Tratado - 20 & $5,8 \pm 1,2$ & (15) & $5,4 \pm 1,3$ & $(15)$ & $11,9 \pm 1,2$ & (15) \\
\hline & Tratado - 200 & $5,3 \pm 2,3$ & (15) & $5,5 \pm 1,5$ & $(15)^{* * *}$ & $12,1 \pm 1,5$ & (15) \\
\hline \multirow[t]{3}{*}{ V } & Controle & $5,4 \pm 1,5$ & (15) & $5,4 \pm 2,2$ & (15) & $11,6 \pm 1,5$ & (15) \\
\hline & Tratado - 20 & $5,4 \pm 1,6$ & (15) & $5,7 \pm 1,7$ & (15) & $12,1 \pm 1,5$ & (15) \\
\hline & Tratado - 200 & $5,6 \pm 1,7$ & (14) & $5,2 \pm 1,5$ & (14) & $11,6 \pm 1,1$ & (14) \\
\hline
\end{tabular}

Resultados expressos em média \pm desvio padrão, ( ) no de casos estudados. ${ }^{*} p<0.05$ em relação aos grupos tratado-20 e tratado-200 (Teste de Dunnet) ** $e^{* * *} p<0.05$ em relação ao grupo controle ( Teste de Dunnet)

dificação do tempo de transporte até 0 útero, prejudicando asincronianecessária dafase do desenvolvimento embrionário, assim como a preparação do endométrio, necessáriaaimplantação $0^{26}$.

0 recolhimento de menor quantidade de pré-embriões, comparativamenteaum grupo demãesnão-expostas, indicamortes do concepto ou retenção no oviduto. A presençade pré-embriõesemfaseatrasada de seudesenvolvimento, levaàsuspeitade ação lesivaque retardouo seu processo de segmentação ou que acelerou seu trânsito pelo oviduto.

Q uando se observaatabela6, verificase que a administração de oxcarbazepina não alterao número de blastocistosexpandidos coletados. Tais dadossão indicativos de que a administração do antiepiléptico não altera os processos de fertilização, clivagem, desenvolvimento de mórulaede blastocisto.

0 utro fator de morte do pré-embrião, refere-se ao transportetubário queéfeito 
por etapas, sendo que, inicialmente o préembrião permanecerá por 2 a 5 dias num ambiente especial, isolado do restante do trato reprodutor pela o clusão de duas junções do oviduto - istmo-ampolar e úterotubária, onde ele encontra os nutrientese as condições adequadas ao seu desenvolvimento norma ${ }^{27,28}$. N este período atingea fase de blastocisto expandido e passa parao útero, onde se implantará.

0 transportedo pré-embrião pode ser alterado por diferentesmotivos, entreeles modificação na contractilidade das fibras musculares da tuba uterina ${ }^{29-31}$ que pode ser alterada por prostaglandinas, produzidaslocalmente ou pelo pré-embrião ${ }^{32,33}$ ou por esteróidessexuaisjáque o estrogênio acelera 0 transporte e a progesterona 0 retarda $25,34-37,28$.

$N$ enhum de tais fatores parece ter sido alterado pela administração de oxcarbazepina visto que tanto o número de pré-embriões recolhidos quanto a média de blastocistos expandidos foi semelhante em todos os grupos estudados. Assim, pode-se dizer que a administração de 0 XC em ratas, não parece alterar os mecanismos fisioló gicos envolvidos com a fertilização, a clivagem e a evolução até blastocisto expandido.

Pode-se, portanto, concluir que, no modelo experimental utilizado nesse trabaIho, não existem evidências de toxicidade da oxcarbazepina para a mãe ou para os pré-embriõesem desenvolvimento.

\section{SUMmarY}

Pre-embryo development in rats treated with oxcarbazepine in the first four days after insemination

Oxcarbazepine is a highly efficcacious antiepileptic drug which has very few side effects and has been poorly investigated as to its effects during human and animal gestation.

\section{Tabela 6 - Índice de perdas de pré-embriões (IPE) em ratasWistar tratadas com $20 \mathrm{mg}$ ou $200 \mathrm{mg}$ de oxcarbazepina / Kg de peso corporal, via gástrica, nos dias 1, 2, 3 ou 4 pós- inseminação, e do 10 ao 40 dia pós- inseminação, e de controles que receberam $0,5 \mathrm{ml}$ de água destilada pela mesma via e mesmos dias de tratamento.}

\begin{tabular}{clccc}
\hline Experimentos & Grupos & IPE (\%) TUD & TUE & Total \\
\hline I & Controle & 25,3 & 14,5 & 20,5 \\
& Tratado-20 & 12,5 & 15,2 & 13,7 \\
& Tratado-200 & 12,3 & 12,6 & 12,4 \\
& Controle & 16,8 & 13,8 & 15,3 \\
& Tratado-20 & 8,2 & 11,5 & 9,7 \\
& Tratado-200 & 12,9 & 11,1 & 17,8 \\
& Controle & 12,4 & 14,8 & 14,2 \\
& Tratado-20 & 13,2 & 12,6 & 12,9 \\
& Tratado-200 & 15,5 & 12,5 & 14,3 \\
& & & & \\
& Controle & 15,4 & 9,5 & 12,8 \\
& Tratado-20 & 11,2 & 19,7 & 15,1 \\
& Tratado-200 & 19,2 & 16,9 & 18,7 \\
& & & & \\
& Controle & 12,9 & 18,5 & 15,5 \\
& Tratado-20 & 16,5 & 15,3 & 15,9 \\
& Tratado-200 & 13,3 & 12,3 & 12,9 \\
\hline
\end{tabular}

IPE = (1-Total de pré-embriões $/$ Total de corpos lúteos) $\times 100$

TUD = tuba uterina direita TUE = tuba uterina esquerda

Não há diferença significativa entre os grupos.

Purpose. To verify if the administration of oxcapazepine to female rats in the first four days ofter fertilization alters the viability or development of the pre-embryo.

METHODS. W istar rats were treated with 20 or $200 \mathrm{mg}$ oxcarbazepine/Kg body weight by oral gavage, 1,2,3,or 4 days after insemination or, consecutively, from the first to de fourth day aiming at veryfing the amount and the development up to the expanded blastocyst stage. Maternal body weight and signs such as hair bristling and alteration of the locomotion activity were observed in order to verify any signs of maternal toxicity. A number of corpora lutea and ovaries weight were noted for the analysis of the animal reproductive capacity.

REsults. N either maternal body weight losses nor any physical alteration indicative of discomfort to the rats was observed. Ovaries weight and number of corpora lutea did not differ between treated and control animals. The average of pre-embryos per mother, the index of embryonic losses, the proportion of expanded blastocysts in relation to the total number of pre-embryos and the average of expanded blastocyst/mother did not differ between treated and control animals.

Conclusions. The data indicate that 


\section{Tabela 7 - Percentual de blastocistosexpandidosobtidos de cornos uterinos de ratas Wistar tratadas com 20mg ou 200mg de oxcarbazepina / Kg de peso corporal, via gástrica, nos dias 1,2,3 ou 4 pós-inseminação, e do 10 ao 40 dia pós-inseminação, e de controles que recebe- ram $0,5 \mathrm{ml}$ de água destilada pela mesma via e mesmos dias de tratamento.}

\begin{tabular}{|c|c|c|c|}
\hline Experimentos & Grupos & \multicolumn{2}{|c|}{ Percentual de Blastocistos } \\
\hline \multirow[t]{3}{*}{ । } & Controle & 91,4 & (139/152) \\
\hline & Tratado - 20 & 90,5 & (143/158) \\
\hline & Tratado - 200 & 89,9 & $(152 / 169)$ \\
\hline \multirow[t]{3}{*}{$\|$} & Controle & 88,6 & (132/149) \\
\hline & Tratado - 20 & 97,0 & $(162 / 167)$ \\
\hline & Tratado - 200 & 92,8 & $(155 / 167)$ \\
\hline \multirow[t]{3}{*}{ III } & Controle & 94,3 & $(148 / 157)$ \\
\hline & Tratado - 20 & 91,3 & (148/162) \\
\hline & Tratado - 200 & 95,4 & $(166 / 174)$ \\
\hline \multirow[t]{3}{*}{ N } & Controle & 97,6 & $(161 / 165)$ \\
\hline & Tratado - 20 & 93,4 & (142/152) \\
\hline & Tratado - 200 & 96,6 & $(144 / 149)$ \\
\hline \multirow[t]{3}{*}{ V } & Controle & 93,2 & $(137 / 147)$ \\
\hline & Tratado - 20 & 97,4 & $(149 / 153)$ \\
\hline & Tratado - 200 & 92,2 & (131/142) \\
\hline
\end{tabular}

oxcarbazepine administered to female rats following the therapeutic procedure mentioned above, did not show any toxic effect on the mother and did not alter the preembryo development. [Rev Ass Med Bras; 46(4): 346-53]

Key wORDS: Oxcarbazepine. Pre-embryo. Rat.

\section{Agradecimentos}

As autoras agradecem ao Dr. Marcelo Q uesado o fornecimento de oxcarbazepina; ao excelente trabalho técnico daBióloga Evelise Rochade Souza e do Sr. Paulo Sérgio do Carmo; à versão para o inglês do resumo em português, realizado pela Prof. Rita de Cássio da Silveira e Sá e à FAPEMIG pelo auxílio CBS - 680/97.

\section{ReferênCIAS Bibliográficas}

1. Hill LM. Effects of drugs and chemicals on the fetus and newborn. Mayo Clin. Proc., 1984; 59: 755-65, apud C astro JRS, Rodrigues AMR. Anticonvulsivantes. In: Bedran JN ed. 0 uso de drogas na gravidez e na lactação. Rio de Janeiro, Guanabara, 1988;122 -33.

2. SvigosJM. Epilepsy and pregnancy. Austr. N .Z. J.O bstet.Gynaecol., 1984; 24: 182-184 apud Castro JRS, RodriguesAMR. Anticonvulsivantes. In: Bedran, JN ed. $O$ uso de drogas na gravidez e nalactação. Rio de Janeiro, Guanabara, 1988;122 - 33 .

3. Counstan DR, Mochizuki TK. Handbook for prescribing medication during pregnancy. $3^{\text {rd }}$ ed. Philadelphia, Lippincott-Raven, 1998; 99-101.

4. Briggs GG, Freman RK, Yaffe SJ. A reference guide to fetal and neonatal risks. Drugs in pregnancy and lactation. $5^{\text {th }}$ ed. N ew York, Lippincott W illiams\& W ilkins, 1998; 139-143. 1092-9.

5. KellyTE, EdwardsP, Rein M Teratogenicity of antiepileptic drugs. Am. J. M ed.Genet., 1984; 19: 451- 58 apud C astroJRS, RodriguesAMR.
Anticonvulsivantes. In: BedranjN ed. 0 uso de drogas na gravidez e na lactação. Rio de Janeiro, Guanabara, 1988; 122 -33.

6. Lewis PJ. D rogas e gravidez. São Paulo: Manole, 1979, 210p.

7. Gram L. Clinical experience with oxcarbazepine. Epilepsia, 1994; 35: S21- S22, 1994.

8. Lloyd P, Flesh G., Dieterle W. Clinical pharmacology and pharmacokinetics of oxcarbazepine. Epilepsia, 1994; 35: S10-S13.

9. MCLeand MJ., Schmutz M, W amil AW, O Ipe $H R$, et al. 0 xcarbazepine: Mechanisms of action. Epilepsia, 1994; 35: S5-S9, 1994.

10. Schwabe S. Clinical development out look of oxcarbazepine. Epilepsia, 1994; 35: S2-S4, 1994.

11. Bülau P, Paar WD, von U nrhuh GE. Pharmacokinetics of oxcarbazepine and 10 - hydroxycarbazepine in the new born child of an oxcarbazepine - treated mother. Eur. J. Clin. Pharmacol., 1988; 34: 311-3, 1988.

12. Friis ML, Kristensen O, Boas]., D alby M. et al. Therapeutic experiences with 947 epileptic out patients in oxcarbazepine treatment. Acta N eurol. Scand.,1988; 87: 224 - 27, 1998.

13. AndermannE. Pregnancy and oxcarbazepine. Epilepsia, 1994; 35: S26.

14. Bennett GD, Amore BM, Finnell RH, W lodarczyk B, Kalhorn TF, Skilles GL et al. Teratogenicity of carbamazepine - 10,11 - epoxide and oxcarbazepine in the SWV mice. J. Pharmacol. Exper. Therapy, 1996; 279: 1237 - 42.

15. Gleich J., Frohberg H. General teratological techniques. In: N eubertD, Merker HJ, Kwasigroch TE. Methods in prenatal toxicology, Massachussetts, PSG Publishing Company, 1977; 94-102.

16. Kato H, Morishige WK, Rotchild I. A quantitative relationship between the experimentally determined number of conceptuses and corpus luteus activity in pregnant rats. Endocrinology, 1979;105: 846-50.

17. Kubová H, MARES, P. Anticonvulsivant action of oxcarbazepine, hydroxycarbamazepine, and carbamazepine against metrazol - induced motor seizure in developing rats. Epilepsia, 1993; 34: 188-92.

18. Beijamini V, Skalisz LL, JocaSRL, Andreatini R. The effect of oxcarbazepine on behavioural despair and learned helplessness. Eur. J. of Pharmacol, 1998; 374: 23-7.

19. Manson JM, Kang YJ. T est methods for assessing female reproductive and developmental toxicology. In: Hayes AW. ed. Principles and Methods of toxicology, 3 ed. N ew York, Raven Press, 1994; 989-1037.

20. Forcelledo ML, VeraR., Croxatto HB. O vum transport in pregnant, pseudopregnant, and cyclic rats and its relationship to estradiol and progesterone blood levels. Biol.Reprod, 1981; 24:760-5.

21. O rtiz ME, LladosC, Croxatto HB. Embryos of different ages transferred to the rat oviduct enter the uterus at different times. Biol. Reprod, 1989; 41: 381- 4.

22. U chida K, Kadowaki M., N omura Y, M yata K, 
Miyake T. et al. Relationship between ovarian progestin secretion and corporaluteafunction in pregnant rat. Endocrinol, 1970; 17: 499 - 507.

23. Waynforth $\mathrm{HB}$. Changes in the volume of rat corpus luteum during pregnancy and after surgical interference with the uterus and placenta. Acta Endocrinol, 1971; 66: 296-302.

24. Inman $O R$, Markivee $C R$. Gross effects on rabbit embryos and newborns of $x$ - irradiation in the blastocyst atage. Anat. Rec.,1963; 147:139-47.

25. O rtiz ME, Villalón $M, C$ roxatto HB. O vum transport and fertility following post ovulatory treatment with estradiol in rats. Biol.Reprod., 1979; 21: 1163-167.

26. Roblero LS, Fernandez $\mathrm{O}, \mathrm{Cr}$ roxatto HB. The effect of RV 486 on transport, development and implantation of mouse embryos. Contraception, 1987;36: p.549-55.

27. Moore GD, C roxatto HB. Effects of delayed treatment with estrogen on the transport of microspheres by the rat oviduct. J. Reprod.Fertil., 1988; 83: 795-802.

28. Croxatto HB, O rtiz ME, Forcelledo ML, Fuentealba $B$ et al. Hormonal control of ovum transport through the rat oviduct. Arch. Biol. Med. Exp., 1991; 24: 403-10.

29. Talo A. How the myosalpix works in gamete and embryo transport. Arch. Biol. M ed.Exp., 1991; 24: 332-43.

30. Villalon M, Verdugo P. C ontrol of ciliary movement in mammalian oviductal ciliated cells. Arch.Biol.M ed.Exp., 1991; 24: 344-50.

31. Harper MJK. Gamete and zygote transport. In: KnobilE,N eillJD. Thephysiology ofreproduction, 2ed. N ew York, Raven Press, 1994; 123-87.

32. Viggiano M, Cebral E, Gimeno AL, Gimeno $M F$. Probable influence of ova and embryo prostaglandins in the differential transport in pregnant and cycling rats. Prostaglandins Leukot Essent. Fatty Acid., 1992; 45: 211-5.

33. Viggiano $M, C$ ebral E, Gimeno AL, Gimeno $M F$. Influence of ova within rat oviducts on spontaneous motility and on prostaglandin production. Prostaglandins Leukot Essent. Fatty Acid., 1990; 41: 13 -7 apud Harper MJK. Gamete and zygote transport. In: Knobil, E, N eill JD. The physiology of reproduction, 2ed. N ew York, Raven Press, 1994;123-87.
34. Forcelledo ML, Morales P, Vera R, Q uijadaS, Croxatto HB. Role of ovarian and adrenal progesterone in the regulation of ovum transport in pregnant rats. Biol.Reprod., 1982; 27: 1033-41.

35. Forcelledo ML, Croxatto HB. Effects of 4hydroxyandrostenedione and exogenoustestosterone on blood concentration of oestradiol and oviductal embryo transport in the rat. J. Endocrinol., 1988; 118: 93-100.

36. FuentealbaB, N ieto M, Croxatto HB. Progesterone abbreviates the nuclear retention of estrogen receptor in the rat oviduct and counteracts action on egg transport. Biol.Reprod., 1988; 38: 63-9.

37. Vinijisamun A. Effects of monoclonal antibody against progesterone on embryo transport, development and implantation in laboratory mice. Reprod.Fertil.Develop., 1990; 2: 395-405.

Artigo recebido: 26/11/99

Aceito para publicação: 18/04/00 